\title{
Effects of 12 weeks of treatment with fermented milk on blood pressure, glucose metabolism and markers of cardiovascular risk in patients with type 2 diabetes: a randomised double-blind placebo-controlled study
}

\author{
K D Hove', C Brøns ${ }^{1,4}$, K Færch', S S Lund', P Rossing 1,2,3 and A Vaag 1,4 \\ ${ }^{1}$ Steno Diabetes Center A/S, Niels Steensens Vej 2, DK-2820 Gentofte, Denmark, ${ }^{2}$ Health, University of Aarhus, \\ Aarhus, Denmark, ${ }^{3}$ NNF Center for Basic Metabolic Research and ${ }^{4}$ Department of Endocrinology, Diabetes and \\ Metabolism, Rigshospitalet, University of Copenhagen, Copenhagen, Denmark
}

Correspondence should be addressed to K D Hove

Email

karinhove@dadlnet.dk

\begin{abstract}
Objective: Studies have indicated a blood pressure (BP)-lowering effect of milk-derived peptides in non-diabetic individuals, but the cardiometabolic effects of such peptides in patients with type 2 diabetes (T2D) are not known. We investigated the effect of milk fermented with Lactobacillus helveticus on BP, glycaemic control and cardiovascular risk factors in T2D. Design: A randomised, double-blinded, prospective, placebo-controlled study.

Methods: In one arm of a factorial study design, 41 patients with T2D were randomised to receive $300 \mathrm{ml}$ milk fermented with L. helveticus (Cardi04 yogurt) ( $n=23$ ) or $300 \mathrm{ml}$ artificially acidified milk (placebo yogurt) ( $n=18)$ for 12 weeks. BPs were measured over 24-h, and blood samples were collected in the fasting state and during a meal test before and after the intervention.

Results: Cardi04 yogurt did not reduce 24-h, daytime or nighttime systolic or diastolic BPs compared with placebo $(P>0.05)$. Daytime and 24-h heart rate (HR) were significantly reduced in the group treated by Cardi04 yogurt compared with the placebo group $(P<0.05$ for both). There were no differences in HbA1c, plasma lipids, $C$-reactive protein, plasminogen activator inhibitor-1, tumour necrosis factor alpha, tissue-type plasminogen activator: Ag, and von Willebrand factor: Ag between the groups. The change in fasting blood glucose concentration differed significantly between the two groups with a larger increase in the placebo group $(P<0.05)$.

Conclusions: Ingestion of milk fermented with $L$. helveticus compared with placebo for 12 weeks did not significantly reduce BP in patients with T2D. Our finding of lower HRs and fasting plasma glucose levels in T2D patients during ingestion of fermented milk needs further validation.
\end{abstract}

\section{Introduction}

Clinical and experimental studies carried out in spontaneously hypertensive rats have reported that biologically active peptides derived from fermented milk has a blood pressure (BP)-lowering effect in hypertensive subjects $(1,2)$. Most of the studies examined the tripeptides isoleucine-proline-proline and valineproline-proline released by degradation of milk proteins (especially casein) during fermentation of milk by lactic acid bacteria such as Lactobacillus helveticus (1). The mechanism of the antihypertensive effect of milk (c) 2015 European Society of Endocrinology Printed in Great Britain
Published by Bioscientifica Ltd. 
peptides is mainly supposed to be the inhibition of the angiotensin-converting enzyme (ACE) by the tripeptides (1). ACE is important in the regulation of BP by converting angiotensin I into the vasoconstrictor angiotensin II and inactivating the vasodilator bradykinin, thereby increasing the BP.

Even a small decrease in BP may be associated with a beneficial effect on cardiovascular disease (CVD) risk. Thus, a recent study has shown that a decrease of $5.6 \mathrm{mmHg}$ in systolic BP (SBP) and $2.2 \mathrm{mmHg}$ in diastolic $\mathrm{BP}$ (DBP) reduced the relative risk of a major macrovascular or microvascular event by $9 \%$ (3). A recent Cochrane review including 15 intervention studies has only found a modest decrease of $2.45 \mathrm{mmHg}$ in SBP with no effect of fermented milk on DBP, thus the authors did not support the use of fermented milk to reduce BP in hypertension (4). However, none of these studies included patients with type 2 diabetes (T2D) who are known to be prone to develop hypertension and who may therefore benefit to a greater extent with respect to cardiovascular morbidity and mortality from having their BP levels reduced. A number of previous studies have reported beneficial metabolic effects of ACE inhibitors or angiotensin II receptor antagonists on insulin secretion, insulin action as well as on overall glucose metabolism in patients with T2D $(5,6)$. In support of this, large-scale randomised prospective trials have reported a decreased incidence of T2D or leading to regression of impaired fasting glucose levels or impaired glucose tolerance to normoglycaemia by ACE inhibitors and angiotensin receptor blockers (ARBs), as primary or secondary outcomes $(7,8)$. Studies on the use of bioactive peptides in diabetic patients are limited, and only a few studies have evaluated the effect of probiotics on specific elements of the metabolic syndrome (MS) in non-diabetic adolescents and adults $(9,10,11)$. Furthermore, the excess risk of CVD in patients with T2D is, besides hypertension, associated with adverse changes in plasma lipid levels as well as with a range of cardiometabolic risk markers involved in subclinical inflammation and coagulation. It is not known to which extent fermented milk may influence plasma lipids, inflammation and/or coagulation. On this background, the aim of the current study was to examine the extent to which 12 weeks intake of milk fermented with L. helveticus (Cardi04 yogurt) reduces BP and/or associated dysmetabolic traits, including insulin resistance, glycaemic control, plasma lipid levels and markers of antithrombosis and low-grade inflammation in $\mathrm{T} 2 \mathrm{D}$ patients.

\section{Design and methods}

\section{Ethics}

The Central Ethics Committee, the Danish Medicine Agency and the Danish Data Protection Agency approved the study. All enrolled patients gave written and oral informed consent, and the study was registered at ClinicalTrials.gov (registration no. NCT00699426).

\section{Study protocol}

The study was a prospective randomised double-blind, placebo-controlled $2 \times 2$ factorial study, addressing the individual effects of both Cardi04 yogurt as well as of esomeprazole on cardiometabolic traits in 41 patients with T2D. The study was performed at the Steno Diabetes Center A/S, Denmark, during the period from 2008 to 2009. The esomeprazole treatment results of the $41 \mathrm{~T} 2 \mathrm{D}$ patients included in this factorial study have been published elsewhere (12).

All patients were recruited using the electronic medical record database at the Steno Diabetes Center $\mathrm{A} / \mathrm{S}$ and were invited by letter to participate in the study. Inclusion criteria were duration of diabetes for more than 1 year, HbA1c levels between 6.0 and 10.0\% (42 and $86 \mathrm{mmol} / \mathrm{mol}$ ), age between 40 and 70 years, being on diet and/or oral glucose-lowering medication only (metformin and sulfonylurea). Exclusion criteria were serious organic or metabolic conditions including malignant disease, liver or severe kidney disease (serum creatinine level above the normal range or macroalbuminuria), severe heart failure (New York Heart Association class III or above), fasting C-peptide concentrations $<0.3 \mathrm{pmol} / \mathrm{l}$, alcohol or drug addiction, severe neuropathy (symptoms + vibration perception threshold $>50 \mathrm{mV}$ measured using a biotensiometer), anaemia, treatment with insulin, neutropaenia, treatment with warfarin or other coumarin derivates or with medication for gastric diseases, pregnancy or breast-feeding. Antihypertensive and antidiabetic medications were allowed on the condition that neither doses nor type of treatment changed during the study period.

Both men and women were invited, but only men accepted participation. A total of 46 patients were found eligible for participation and were subsequently enrolled in the study. However, five patients were excluded before randomisation. One patient dropped out for personal reasons, one dropped out because of a cancer diagnosis and three persons were excluded after screening: one because of alcohol abuse, one had anaemia and one 
with elevated liver enzyme levels. The remaining 41 participants completed the study protocol (Fig. 1).

The subjects were randomly assigned by a computerised randomisation system to receive either $300 \mathrm{ml}$ Cardi04 yogurt containing Lactobacillus $(n=23)$ once daily or $300 \mathrm{ml}$ artificially acidified milk $(n=18)$. The patients were concurrently randomly assigned to receive either esomeprazole $40 \mathrm{mg}$ or matching placebo with a $2 \times 2$ factorial design as previously described (12). The allocation sequence was concealed in sealed envelopes and locked away from the researcher enrolling and assessing participants. The research staff and study participants remained blinded to the type of treatment during the entire study.

Cardi04 yogurt was delivered to the home address of the participants every 3rd week in coded opaque bottles. The bottles containing either Cardi04 yogurt or placebo looked identical, and the participants were instructed to consume the $300 \mathrm{ml}$ fermented milk every morning for 12 weeks. A diary leaflet was given to the participants to confirm the intake and to report any potential side effects and to record blood glucose levels. The diary was presented at each visit. For the duration of the study, the subjects were asked to maintain their normal diet and lifestyle.

At each visit adverse effects, changes in body weight, medication, lifestyle, and acute illness were documented. Compliance was assessed by patient interview and from the diaries. A physician monitored the compliance at each clinic visit.

\section{Fermented milk}

L. helveticus Cardi04 is a natural lactic acid bacterium. Cardi04 yogurt is a drinking yogurt that is made from

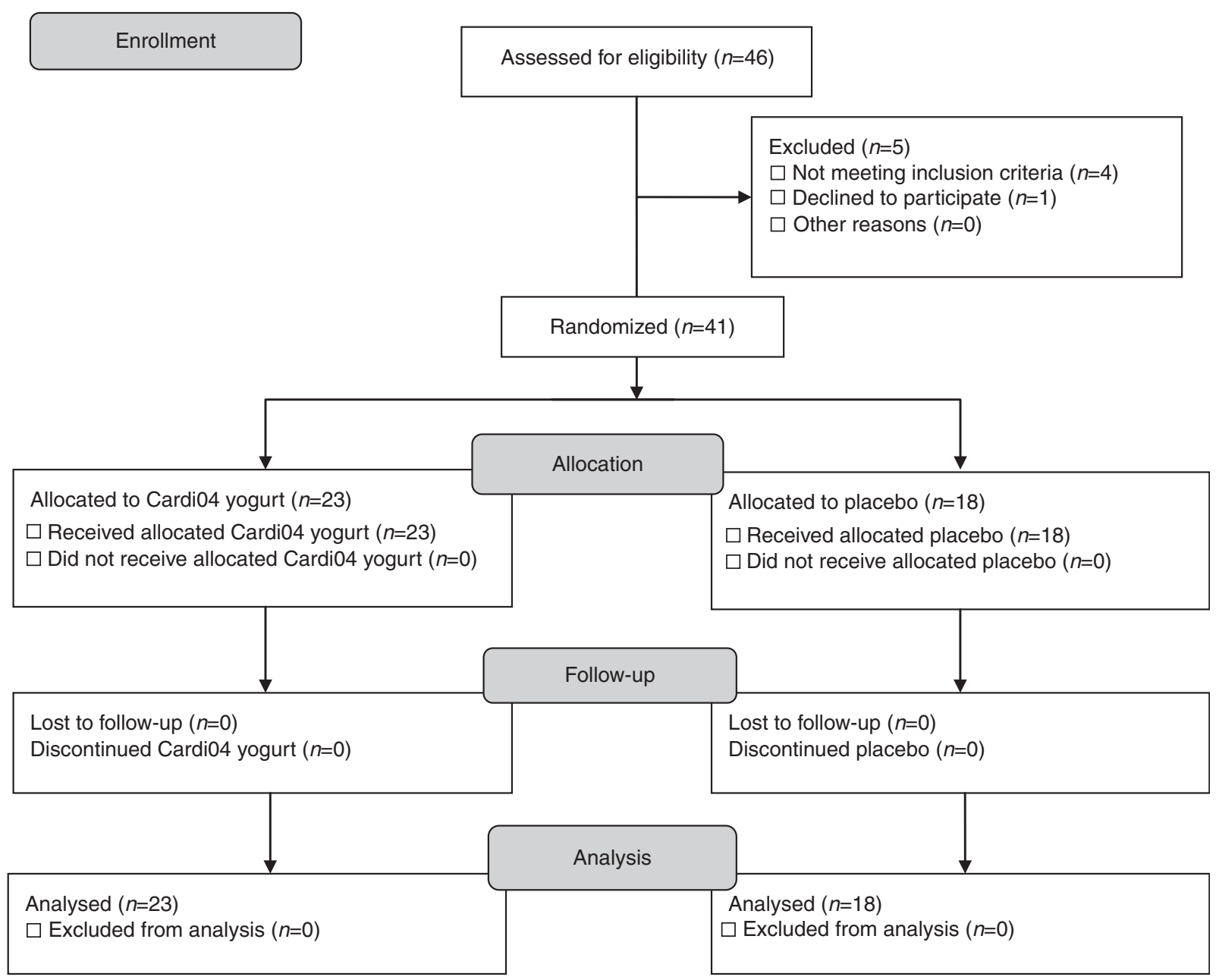

\section{Figure 1}

Patient recruitment flow diagram. 
skimmed milk fermented by L. helveticus. The L. helveticus fermented milk (Cardi04) was prepared from pasteurised $\left(90^{\circ} \mathrm{C}\right.$, $60 \mathrm{~min}$ ) skimmed milk, cooled to $43^{\circ} \mathrm{C}$, added artificial sweetener (sucralose) and inoculated with $1 \%$ (w/t) starter culture containing a pure strain of L. helveticus Cardi04 and fermented at $43^{\circ} \mathrm{C}$ at $\mathrm{pH} 4.05(\sim 7-8 \mathrm{~h})$. The placebo product, artificially acidified milk, was prepared by adding glucono- $\delta$-lactone $1.75 \%$ instead of L. helveticus Cardi04, otherwise following the same protocol. There was no difference in mineral content between the active and the placebo products. After fermentation, peach flavour and pectin-solution were added and the fermented milk was pasteurised, homogenised and dispensed in $300 \mathrm{ml}$ bottles.

\section{Examinations}

The patients visited the department four times during the 3-month study period: i) the inclusion day; ii) the baseline test and randomisation day; iii) after 6 weeks for clinical assessment and check of compliance; and iv) after 12 weeks for the final examination and outcome measures. On the test days, the participants were admitted in the morning to the Diabetes Research Unit. After a 10-h overnight fast, an i.v. cannula was inserted into a forearm vein.

A standard $2200 \mathrm{~kJ}$ meal tolerance test $(55 \%$ carbohydrate, $30 \%$ fat, and $15 \%$ protein) ingested over $10 \mathrm{~min}$ was performed. Blood samples were drawn 10 min before and at $0,15,30,60,90,120$, and $180 \mathrm{~min}$ after the meal intake. On the day before the last meal test, the patients were taking the study product twice a day as well as with the meal on the day of the meal test. This was done to achieve maximum ability to identify whether the dietary supplement had an effect on diabetes and to ensure that a negative study would not be attributed to an inadequate dose.

\section{Biochemical analyses and calculations}

Plasma glucose concentrations were determined by the hexokinase glucose-6-phosphate dehydrogenase enzymatic assay method using an automated analyser (Roche Hitachi 912 model). Plasma insulin concentrations were measured using solid-phase two-site fluoroimmunometric assays (AutoDELFIA insulin kit, Wallac, Turku, Finland). HbA1c measurements were obtained using ion-exchange HPLC (Tosoh HLC-723 G7, Tokyo, Japan) for routine analysis. Plasma proinsulin and C-peptide concentrations were measured using the AutoDELFIA C-peptide kit
(Wallac). Serum triglyceride (TG), HDL, LDL, and total cholesterol levels were analysed using the specific ABX Penta kits on Pentra 400 analysers.

High sensitivity serum C-reactive protein (CRP) test was carried out by a nephelometric method, using antibodies, reagents, and equipment from Dade Behring, Marburg, Germany. Tumour necrosis factor alpha (TNF $\alpha)$ in plasma was determined by the Human TNF $\alpha$ Quantikine HS ELISA system from R\&R Systems, Abingdon, UK. The protein concentration of tissue-type plasminogen activator (t-PA) was determined by ELISA method using the TintElize t-PA kit from Biopool (Umeå, Sweden). Plasminogen activator inhibitor-1 (PAI1) was determined by ELISA, using the TriniLIZE PAI kit from Trinity Biotech (Jamestown, NY, USA). Von Willebrand factor (vWF) was determined by an ELISA method using antibodies from DAKO (Glostrup, Denmark).

The homeostasis model assessment of insulin resistance (HOMA-IR) was calculated according to the formula: fasting glucose $(\mathrm{mmol}) \times$ fasting insulin $(\mu \mathrm{U} / \mathrm{ml}) / 22.5$. Total areas under the curves (AUC) for insulin and glucose responses were calculated using the trapezoidal rule.

\section{BP measurements}

The patients' 24-h ambulatory BP (AMBP) was measured with an automatic 24/h BP recorder Takeda TM2421 oscillometric device (A\&D Medical, Tokyo, Japan) at baseline and at the end of the intervention period. BP and heart rate (HR) readings were obtained every $30 \mathrm{~min}$ during the day (0700-2300 $\mathrm{h}$ ) and every 60 min during the night (2300-0700 h) for $24 \mathrm{~h}$ from the non-dominant arm.

The recording was then analysed to obtain daytime, nighttime and 24-h SBP, DBP and HRs after averaging values obtained for each hour respectively.

Waist and hip circumference was measured using a flexible measuring tape (Meterex, Langenfeld, Germany). All adverse events (AEs) experienced during the study were reported on a clinical report form. The intensity of the $\mathrm{AE}$ was graded on a three-point scale (mild, moderate or severe) and was reported in detail on the clinical report form. The relationship of the $\mathrm{AE}$ with the treatment was assessed by the investigator.

\section{Statistical analysis}

The primary endpoint of the combined $2 \times 2$ factorial study of the effects of esomeprazole and fermented milk on cardiometabolic risk factors in T2D patients was change in insulin secretion as explained previously (12). We had an 
$80 \%$ power to detect a $25 \%$ change in this outcome. In a post hoc power calculation of the primary endpoint of interest for the fermented milk study reported here, we had an almost $80 \%$ power to detect a $5 \mathrm{mmHg}$ difference in the 24-h DBP. Linear regression analysis (ANOVA) was used to test differences in response to treatment between groups. The effects of Cardi04 yogurt treatment were tested for potential interactions with the esomeprazole treatment. Non-normally distributed variables were logarithmically transformed before analysis (results given as medians with interquartile range). Normally distributed variables are presented as means \pm s.D. unless otherwise specified. A $P$ value $<0.05$ was considered statistically significant. All analyses were performed using the Statistical Analysis System (SAS 9.2; SAS Institute, Cary, NC, USA). All analyses studying the effect of Cardi04 yogurt treatment were performed with and without adjustment for the esomeprazole intervention. Sample size calculation was based on the esomeprazole treatment as previously described (12).

\section{Coefficients of variation for the assays}

The intra- and inter-assay coefficients of variation (CV) were 0.3 and $0.9 \%$ at $\mathrm{HbA} 1 \mathrm{c}$ concentration 52.0 and
$51.3 \mathrm{mmol} / \mathrm{mol}$. The intra- and inter-assay $\mathrm{CV}$ were 3.7 and $9.0 \%$ at p-proinsulin concentration $2.5 \mathrm{pmol} / \mathrm{l}$. The intra- and inter-assay CV were 2.1 and $6.3 \%$ at p-insulin concentration 34 and $33 \mathrm{pmol} / \mathrm{l}$. The intra- and inter-assay CV were 1.3 and 3.5\% at C-peptide concentration 1095 and $1108 \mathrm{pmol} / \mathrm{l}$. The intra- and inter-assay CV were 0.7 and $0.9 \%$ at p-glucose concentration $4.2 \mathrm{mmol} / \mathrm{l}$. The intra- and inter-assay CV were 0.8 and $1.40 \%$ at p-cholesterol levels 3.7 and $4.09 \mathrm{mmol} / \mathrm{l}$ respectively. The intra- and inter-assay CV were 0.7 and $1.4 \%$ at P-TG concentration $1.4 \mathrm{mmol} / \mathrm{l}$. The intra- and inter-assay $\mathrm{CV}$ were 1.2 and $2.8 \%$ at P-HDL concentration 1.1 and $0.9 \mathrm{mmol} / \mathrm{l}$. The inter-assay CV for P-CRP was $6.3 \%$. The intra- and inter-assay $\mathrm{CV}$ were 4.9 and $5.4 \%$ at t-PA concentration of $15 \mathrm{ng} / \mathrm{ml}$. The intra- and inter-assay CV were 2.9 and $3.3 \%$ at PAI1 concentration $40 \mathrm{ng} / \mathrm{ml}$. The inter-assay CV was $9.5 \%$ for vWF. The intra- and interassay CV were 8.8 and $16.7 \%$ at P-TNF $\alpha$ concentrations 2.6 and $2.4 \mathrm{pg} / \mathrm{ml}$.

\section{Results}

Table 1 gives the characteristics of patient at baseline and after treatment for the two groups.

Table 1 Clinical characteristics of patients before and after Cardi04 yogurt or placebo treatment. Data are means (s.D.) or medians (interquartile range). Statistically significant values $(P<0.05)$ are in boldface.

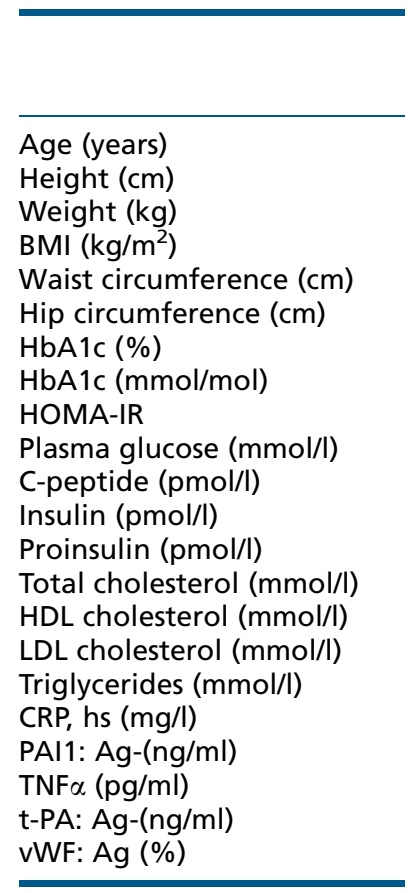

\begin{tabular}{c}
\hline Cardio4 yog \\
\hline Before \\
\hline $58.5(7.7)$ \\
$178.1(7.4)$ \\
$93.2(17.9)$ \\
$29.2(3.8)$ \\
$101.3(11.3)$ \\
$105.0(8.9)$ \\
$6.8(0.5)$ \\
$51(3.3)$ \\
$3.6(1.5 ; 4.7)$ \\
$8.0(7.1 ; 9.1)$ \\
$1008(674 ; 1250)$ \\
$50(28.5 ; 84.5)$ \\
$26(16.5 ; 40)$ \\
$3.6(0.7)$ \\
$1.2(0.3)$ \\
$1.7(0.7)$ \\
$1.4(1.1 ; 1.8)$ \\
$0.7(0.4 ; 2.1)$ \\
$35.8(13.4)$ \\
$1.1(0.3)$ \\
$12.7(3.9)$ \\
$120.3(30.9)$ \\
\hline
\end{tabular}

\begin{tabular}{c}
\hline \multicolumn{1}{c}{ Placebo (} \\
\hline Before \\
\hline $60.6(5.2)$ \\
$175.4(6.0)$ \\
$85.2(9.5)$ \\
$27.7(3.3)$ \\
$100.3(10.5)$ \\
$101.0(6.7)$ \\
$7.3(0.6)$ \\
$56(3.1)$ \\
$2.5(1.7 ; 4.4)$ \\
$9.1(7.5 ; 10.5)$ \\
$817(556 ; 1270)$ \\
$43.5(30 ; 65.5)$ \\
$25.0(17.5 ; 34.5)$ \\
$3.8(0.9)$ \\
$1.1(0.3)$ \\
$1.8(0.8)$ \\
$1.4(0.9 ; 3.1)$ \\
$1.6(1.1 ; 3.1)$ \\
$31.7(16.5)$ \\
$1.3(0.8)$ \\
$13.4(4.1)$ \\
$131.7(37.1)$ \\
\hline
\end{tabular}

\begin{tabular}{c} 
gurt $(n=23)$ \\
After \\
\hline- \\
- \\
$93.3(17.8)$ \\
$29.2(3.8)$ \\
$102.3(11.2)$ \\
$104.5(10.0)$ \\
$7.1(0.6)$ \\
$54(3.1)$ \\
$2.6(1.7 ; 5.1)$ \\
$7.9(7.0 ; 9.6)$ \\
$1030(641 ; 1367)$ \\
$52(36 ; 88)$ \\
$25(20 ; 47.5)$ \\
$3.9(1.0)$ \\
$1.1(0.3)$ \\
$2.0(0.8)$ \\
$1.4(1.1 ; 2.4)$ \\
$0.6(0.4 ; 1.6)$ \\
$35.8(18.5)$ \\
$1.2(0.4)$ \\
$13.1(3.4)$ \\
$125.7(33.1)$ \\
\end{tabular}

\begin{tabular}{c} 
After \\
\hline- \\
- \\
$85.2(9.1)$ \\
$27.7(3.2)$ \\
$99.9(11.7)$ \\
$00.7(7.0)$ \\
$7.7(0.9)$ \\
$61(2.5)$ \\
$2.7(1.9 ; 3.4)$ \\
$9.9(8.2 ; 12.8)$ \\
$771(589 ; 1325)$ \\
$39.0(32.5 ; 73.5)$ \\
$30.3(19.5 ; 44)$ \\
$4.1(1.1)$ \\
$1.2(0.3)$ \\
$1.9(0.8)$ \\
$1.8(1.1 ; 2.6)$ \\
$1.9(0.9 ; 3.1)$ \\
$33.1(13.1)$ \\
$1.6(1.2)$ \\
$14.7(4.5)$ \\
$47.8(45.7)$ \\
\hline
\end{tabular}

\begin{tabular}{cccc}
\hline & & \\
$\boldsymbol{P}$ unadj. & & & $\boldsymbol{P}$ adj. $^{\mathrm{b}}$ \\
\cline { 1 - 1 }- & & - \\
- & & - \\
0.882 & & 0.583 \\
0.797 & & 0.573 \\
0.233 & & 0.211 \\
0.764 & & 0.604 \\
0.940 & & 0.740 \\
& & \\
0.446 & & 0.525 \\
0.046 & & 0.022 \\
0.424 & & 0.616 \\
0.353 & & 0.628 \\
0.223 & & 0.351 \\
0.976 & & 0.835 \\
0.115 & & 0.092 \\
0.959 & & 0.851 \\
0.626 & & 0.270 \\
0.664 & & 0.151 \\
0.752 & & 0.877 \\
0.142 & & 0.197 \\
0.320 & & 0.171 \\
0.077 & & 0.058 \\
& &
\end{tabular}

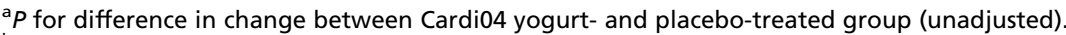

${ }^{\mathrm{b}} P$ for difference in change between Cardi04 yogurt- and placebo-treated group (adjusted for esomeprazole, age, and baseline value). 
Despite the double-blind randomisation, the yogurt and placebo groups differed at baseline with regard to a number of markers related to glucose regulation: HbA1c $(P=0.009)$, fasting glucose concentration $(P<0.001)$, AUC-glucose $(P=0.001)$, AUC-C-peptide $(P=0.026)$, AUC-insulin $(P=0.021)$ (Fig. 2). However, in the analyses of changes in all variables, we have adjusted for the baseline value. All other variables were not statistically significant between groups $(P>0.05)$.

\section{Effect of yogurt on glucose and insulin metabolism, lipids and inflammatory markers}

The change in fasting blood glucose concentration was significantly different between the two groups, with a larger increase in the placebo group during the 12-week intervention. There was no interaction between Cardi04 yogurt and esomeprazole on fasting plasma glucose concentration $(P=0.87)$. There were no significant differences between the groups with regards to lipids or inflammatory markers. All measurements were within the normal range and no change was found between groups. There was no significant change in the AUCs for glucose (Fig. 2A) or proinsulin (Fig. 2B) during the meal test after
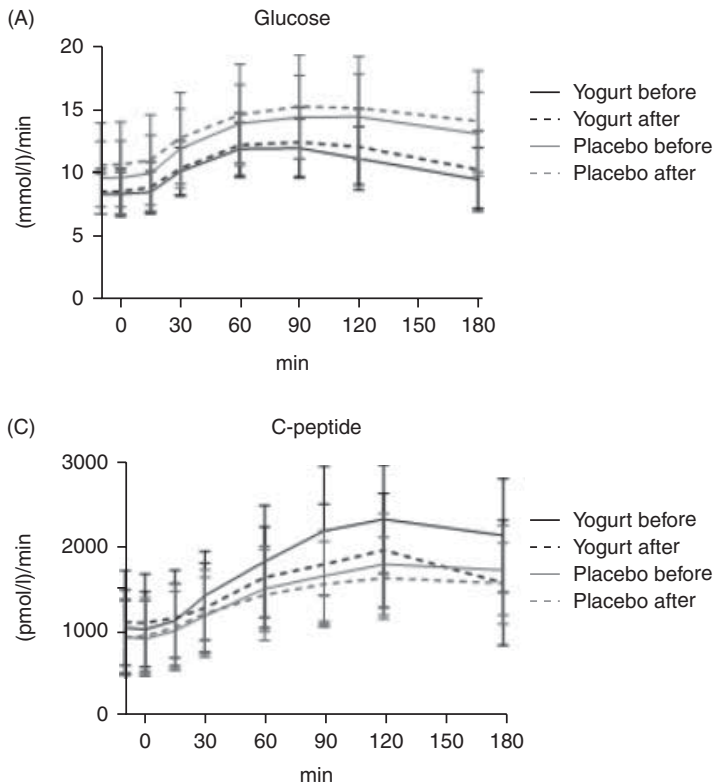

\section{Figure 2}

(A) Plasma glucose, (B) plasma proinsulin, (c) plasma C-peptide, (D) plasma insulin over 0-180 min during the meal test before Cardi04 yogurt treatment $(n=23)$ (solid black line), after Cardi04 yogurt treatment $(n=23)$ (dotted black), before treatment with Cardi04 yogurt or placebo. The AUC for C-peptide decreased significantly after both Cardi04 yogurt and placebo treatment (Fig. 2C). There was no significant change in AUCs for plasma insulin levels (Fig. 2D).

\section{Changes in 24-h AMBP and HR in response to yogurt treatment}

As given in Table 2, the Cardi04 yogurt treatment did not significantly affect BP. There was no significant change in daytime, nighttime or 24-h SBP during the study. Furthermore, no significant changes were observed in daytime, nighttime or 24-h DBP either during the study. A significant, but small, reduction was observed in daytime HR in the Cardi04 yogurt group compared with placebo. The change in nighttime HR did not differ between the groups. However, 24-h HR decreased significantly in the Cardi04 yogurt group compared with the placebo group. There was no interaction with esomeprazole treatment on daytime HR or 24-h HR ( $P$ for both $>0.05$ ).

Treatment with Cardi04 yogurt was generally well tolerated. Only one patient reported a minor AE of flatulence. In the placebo group, five patients reported
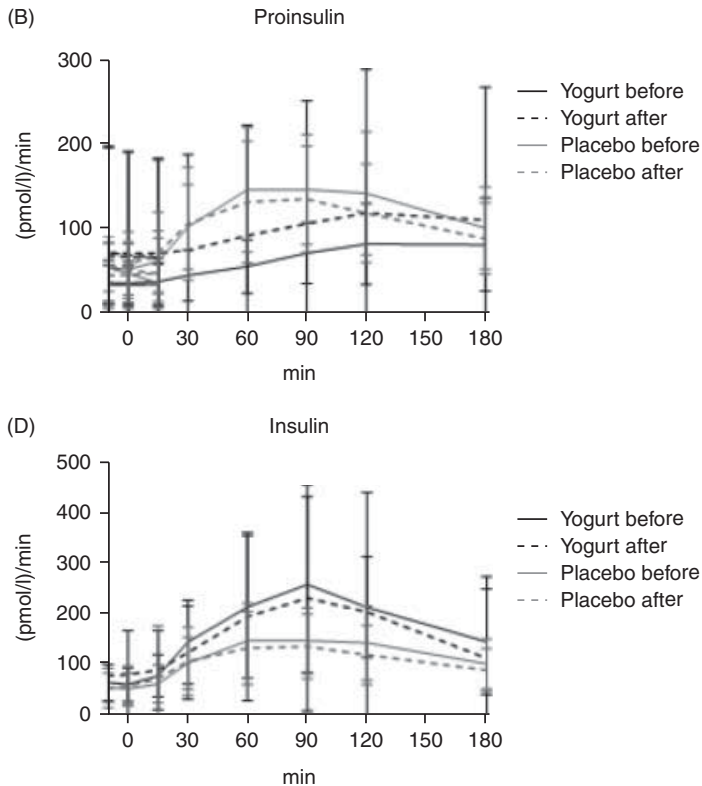

placebo treatment $(n=18)$ (solid grey) and after placebo treatment (dotted grey). Data are means \pm s.D.; $P<0.05$ for difference in C-peptide AUC before and after treatment. 
Table 2 Ambulatory blood pressure monitoring parameters and $\Delta$ ambulatory blood pressure values. Data are means \pm s.D. Statistically significant values $(P<0.05)$ are in boldface.

\begin{tabular}{|c|c|c|c|c|c|c|}
\hline & \multicolumn{2}{|c|}{ Cardi04 yogurt $(n=23)$} & \multicolumn{2}{|c|}{ Placebo $(n=18)$} & \multirow[b]{2}{*}{$P$ unadj. ${ }^{a}$} & \multirow[b]{2}{*}{$P$ adj. ${ }^{b}$} \\
\hline & Before & After & Before & After & & \\
\hline Daytime SBP (mmHg) & $143(18)$ & $140(16)$ & $144(16)$ & $147(16)$ & 0.329 & 0.214 \\
\hline Daytime DBP (mmHg) & $73(7)$ & $71(8)$ & $72(6)$ & $72(7)$ & 0.417 & 0.400 \\
\hline Daytime heart rate (bmp) & $78(9)$ & $76(9)$ & $76(10)$ & $78(11)$ & 0.041 & 0.020 \\
\hline Night-time SBP (mmHg) & $123(22)$ & $120(15)$ & $127(21)$ & 129 (19) & 0.747 & 0.243 \\
\hline Night-time DBP (mmHg) & $62(8)$ & $61(7)$ & $62(7)$ & $63(6)$ & 0.584 & 0.285 \\
\hline Night-time heart rate (bmp) & $69(10)$ & $69(7)$ & 71 (13) & $72(10)$ & 0.442 & 0.190 \\
\hline 24-h SBP $(\mathrm{mmHg})$ & $136(19)$ & $133(14)$ & $138(17)$ & $140(16)$ & 0.465 & 0.218 \\
\hline 24-h DBP (mmHg) & $69(7)$ & $67(5)$ & $68(5)$ & $69(6)$ & 0.448 & 0.377 \\
\hline 24-h heart rate (bmp) & $75(9)$ & $73(7)$ & $74(11)$ & $76(10)$ & 0.061 & 0.037 \\
\hline
\end{tabular}

${ }^{\text {a }} P$ for difference in change between Cardi04 yogurt- and placebo-treated group (unadjusted).

${ }^{\mathrm{b}} P$ for difference in change between Cardi04 yogurt- and placebo-treated group (adjusted for esomeprazole, age, use of blood pressure lowering treatment, and baseline value).

minor AEs: three of them reported flatulence and two patients reported diarrhoea. The AEs mentioned had no impact on compliance of the patients.

\section{Discussion}

The effect of 12 weeks of daily intake of yogurt fermented with L. helveticus (Cardi04 yogurt) on 24-h BP, HR, insulin secretion, glucose metabolism and markers of cardiovascular risk was studied in subjects with T2D. No beneficial effects were found on 24-h BP measurements, insulin secretion, post-prandial glucose levels or on the levels of a number of known cardiometabolic markers involved in subclinical inflammation and/or coagulation. However, we found a reduced average HR of $2 \mathrm{bpm}$ over $24 \mathrm{~h}$ and during daytime. Furthermore, fasting plasma glucose levels increased among patients in the placebo group compared with group treated with Cardi04 yogurt over the 12 weeks of intervention period.

As for the primary end-point in this study, we did not find any statistically significant differences in daytime, nighttime or 24-h BP between Cardi04 yogurt and placebo groups. This is in accordance with the findings by Usinger et al. (13) who reported no significant effect of a similar amount of Cardi04 yogurt on 24-h BP measurements in a group with prehypertension or borderline hypertension. Our result is also supported by two other studies investigating at the effect of lactotripeptides on 24-h AMBP monitoring (ABPM) without finding any significant effect $(14,15)$. Two studies using 24-h ABPM found a significant effect of lactotripeptides $(16,17)$. Other studies have investigated at the effect of different types of milk peptides in patients with hypertension. Some meta-analyses have shown a significant effect on resting $\mathrm{BP}$ as measured at one standard time point during the day $(18,19,20)$. A metaanalysis of the data from 15 studies showed a small effect on SBP, but no effect on DBP, as mentioned previously (4). Similarly, a recent meta-analysis of 14 studies assessing the BP-lowering effect of the peptides isoleucine-prolineproline and valine-proline-proline exclusively in European subjects has shown a small decrease in SBP and DBP of 1.28 and $0.59 \mathrm{mmHg}$ respectively (21). It cannot be ruled out that the use of BP-lowering medication, ACE/AT2 blockers in our study might have influenced the results; however, we do not find this likely as both dose and type of antihypertensive medication were kept constant during the study period.

Interestingly, we found a statistically significant lower daytime and 24-h HR in patients ingesting Cardi04 yogurt. A similar effect on HR has also been shown in spontaneously hypertensive rats fed by L. helveticus fermented milk (22), and could theoretically be ascribed to the ACE inhibitory effects of L. helveticus (23). Indeed, angiotensin II activates the sympathetic nervous system and it was previously reported that treatment with ACE inhibitors reduce the $H R$ in hypertensive patients with elevated HR values (and presumably higher sympathetic activity) (23). $\mathrm{HR}$ is an important determinant of myocardial oxygen consumption and cardiac work. An elevated $\mathrm{HR}$ is generally considered as an important risk factor for CVD, and therefore a reduction in $\mathrm{HR}$ may represent an important goal in the treatment of patients with a wide range of cardiac disorders $(24,25)$. However, it is important to bear in mind that the ACE inhibition of fermented milk shown in animal and in in vitro studies has not been conclusively shown in humans.

The deterioration of the fasting plasma glucose level in the T2D patients during the 12-week study in the 
placebo group could theoretically be explained by the progressive nature of T2D with a decline of $\beta$-cell function over time (26). This is supported by the significant decline in insulin secretion as determined by the AUC C-peptide levels in both groups during the intervention (Fig. 2). The finding of a statistical significantly reduced deterioration of the fasting plasma glucose level in patients ingesting Cardi04 yogurt is interesting. However, this finding should be interpreted cautiously, because imbalances were observed at baseline in various glycaemic variables including the fasting plasma glucose levels. While the differences in fasting plasma glucose levels remained statistically significant even after adjustment for baseline differences between groups, no differences were observed in post prandial or AUC plasma glucose levels between the intervention groups (Fig. 2). Increased activity of the renin angiotensin system has been associated with obesity and glucose intolerance, and prospective epidemiological studies have reported that blocking the system using either ACE inhibitors or ARBs has been shown to reduce the incidence of diabetes $(27,28,29,30)$ and both ACE-inhibitors and ARBs may improve insulin action to different extents $(31,32)$ as well as insulin secretion (33). Accordingly, it may be considered biologically plausible that bioactive peptides in the Cardi04 yogurt inhibiting ACE may reduce plasma glucose levels in patients with diabetes. As for the potential mechanisms, in this study, we found that there was a trend towards an improvement in HOMA insulin resistance in the group that was treated with Cardi04 yogurt compared with placebo (Table 1). Further studies are needed to substantiate this finding.

Subclinical inflammation is commonly present in patients with T2D and the MS (34) and has furthermore been considered a risk factor for arteriosclerosis (35). Probiotic dairy products may theoretically exhibit beneficial effects on the markers of subclinical inflammation by influencing the gut microbiota (36), or via other indirect mechanisms such as the documented improvement in fasting plasma glucose levels. We therefore studied a range of key markers of subclinical inflammation in the circulation including high-sensitive CRP and TNF $\alpha$ levels, and found no difference in these markers between groups (Table 1). Accordingly, the data does not suggest that Cardi04 yogurt may reduce CVD risk by reducing subclinical inflammation.

Several markers of coagulation and to some extent endothelial function including vWF and tPA-Ag and PAI1 Ag are linked with markers of subclinical inflammation and may represent independent risk factors for CVD (37). Indeed, it has been reported that some types for probiotic bacteria influence markers of coagulation in a beneficial manner (38). However, we found no effect of Cardi04 yogurt on any of the key markers of coagulation measured in this study.

Hypercholesterolaemia is a major risk factor for CVD, especially a high level of LDL-cholesterol in the blood increases the risk of developing CVD (39). Fermented milk may also be able to improve cholesterol levels (40). However, our study showed no significant differences in total cholesterol, LDL cholesterol, HDL cholesterol, and serum TG levels between Cardi04 yogurt and placebo groups (Table 1).

The strength of this study is that the study was performed in a randomised, double-blind, placebocontrolled manner with ABPM as a state-of-the-art method to measure $\mathrm{BP}$, removing the influence of 'the white-coat effect'.

Limitations are the relatively small number of participants in each group. Furthermore, the study had a relatively short intervention period (12 weeks), which could mask long-term treatment effects. However, within this time period indeed a possible effect is likely to occur. Thus, trials carried out in hypertensive individuals have shown that the largest part of the total BP reduction is observed after 1-2 weeks of treatment followed by a gradual BP-lowering effect until a maximum effect is reached after about 8-12 weeks of treatment (1).

In conclusion, we were unable to show any BPlowering effect of Cardi04 yogurt supplementation for 12 weeks in patients with T2D using AMBP as the primary outcome. However, Cardi04 yogurt reduced fasting plasma glucose levels as well as the daytime- and 24-h HR. These findings needs further confirmation and evaluation with respect to the putative health-promoting effects, and the underlying mechanisms for these effects should be assessed in future studies.

\section{Declaration of interest}

$\mathrm{K}$ Færch and P Rossing are employed by Steno Diabetes Center A/S, a research hospital working in the Danish National Health Service and owned by Novo Nordisk A/S. Steno Diabetes Center A/S receives part of its core funding from unrestricted grants from the Novo Foundation and Novo Nordisk A/S. K D Hove, K Færch, P Rossing, A Vaag, and C Brøns own shares in Novo Nordisk A/S. S S Lund is employed by Boehringer Ingelheim, Germany and owns shares in Novo Nordisk A/S. No other potential conflicts of interest relevant to this article were reported.

\section{Funding}

The study was funded by Steno Diabetes Center A/S, Novo Nordisk A/S and Christian Hansen A/S. 


\section{Author contribution statement}

A Vaag and K D Hove designed the study. The data were analysed and interpreted by all authors. All authors contributed to critical revision of the article. All authors gave their final approval of the current version to be published.

\section{Acknowledgements}

Laboratory technicians M Modest and L Sander Koch (Steno Diabetes Center A/S) provided valuable assistance on the test days. Special thanks is extended to all the research volunteers for their participation.

\section{References}

1 Boelsma E \& Kloek J. Lactotripeptides and antihypertensive effects: a critical review. British Journal of Nutrition 2009101 776-786. (doi:10.1017/S0007114508137722)

2 Sipola M, Finckenberg P, Santisteban J, Korpela R, Vapaatalo H \& Nurminen ML. Long-term intake of milk peptides attenuates development of hypertension in spontaneously hypertensive rats. Journal of Physiology and Pharmacology 200152 745-754.

3 Patel A, Group AC, MacMahon S, Chalmers J, Neal B, Woodward M, Billot L, Harrap S, Poulter N, Marre M et al. Effects of a fixed combination of perindopril and indapamide on macrovascular and microvascular outcomes in patients with type 2 diabetes mellitus (the ADVANCE trial): a randomised controlled trial. Lancet $2007 \mathbf{3 7 0}$ 829-840. (doi:10.1016/S0140-6736(07)61303-8)

4 Usinger L, Reimer C \& Ibsen H. Fermented milk for hypertension. Cochrane Database of Systematic Reviews 20124 CD008118. (doi:10.1002/14651858)

5 Padwal R \& Laupacis A. Antihypertensive therapy and incidence of type 2 diabetes: a systematic review. Diabetes Care 200427 247-255. (doi:10.2337/diacare.27.1.247)

6 Scheen AJ. Prevention of type 2 diabetes mellitus through inhibition of the Renin-Angiotensin system. Drugs 200464 2537-2565. (doi:10.2165/00003495-200464220-00004)

7 Group NS, McMurray JJ, Holman RR, Haffner SM, Bethel MA, Holzhauer B, Hua TA, Belenkov Y, Boolell M, Buse JB et al. Effect of valsartan on the incidence of diabetes and cardiovascular events. New England Journal of Medicine 2010362 1477-1490. (doi:10.1056/ NEJMoa1001121)

8 Investigators DT, Bosch J, Yusuf S, Gerstein HC, Pogue J, Sheridan P, Dagenais G, Diaz R, Avezum A, Lanas F et al. Effect of ramipril on the incidence of diabetes. New England Journal of Medicine $2006 \mathbf{3 5 5}$ 1551-1562. (doi:10.1056/NEJMoa065061)

9 Gobel RJ, Larsen N, Jakobsen M, Molgaard C \& Michaelsen KF. Probiotics to adolescents with obesity: effects on inflammation and metabolic syndrome. Journal of Pediatric Gastroenterology and Nutrition 201255 673-678. (doi:10.1097/MPG.0b013e318263066c)

10 Andreasen AS, Larsen N, Pedersen-Skovsgaard T, Berg RM, Moller K, Svendsen KD, Jakobsen M \& Pedersen BK. Effects of Lactobacillus acidophilus NCFM on insulin sensitivity and the systemic inflammatory response in human subjects. British Journal of Nutrition $2010 \mathbf{1 0 4}$ 1831-1838. (doi:10.1017/S0007114510002874)

11 Laitinen K, Poussa T, Isolauri E \& Nutrition, Allergy, Mucosal Immunology and Intestinal Microbiota Group. Probiotics and dietary counselling contribute to glucose regulation during and after pregnancy: a randomised controlled trial. British Journal of Nutrition 2009101 1679-1687. (doi:10.1017/S0007114508111461)

12 Hove KD, Brons C, Faerch K, Lund SS, Petersen JS, Karlsen AE, Rossing P, Rehfeld JF \& Vaag A. Effects of 12 weeks' treatment with a proton pump inhibitor on insulin secretion, glucose metabolism and markers of cardiovascular risk in patients with type 2 diabetes: a randomised double-blind prospective placebo-controlled study. Diabetologia 2013 56 22-30. (doi:10.1007/s00125-012-2714-y)

13 Usinger L, Jensen LT, Flambard B, Linneberg A \& Ibsen H. The antihypertensive effect of fermented milk in individuals with prehypertension or borderline hypertension. Journal of Human Hypertension 201024 678-683. (doi:10.1038/jhh.2010.4)

14 Engberink MF, Schouten EG, Kok FJ, van Mierlo LA, Brouwer IA \& Geleijnse JM. Lactotripeptides show no effect on human blood pressure: results from a double-blind randomized controlled trial. Hypertension 200851 399-405. (doi:10.1161/HYPERTENSIONAHA. 107.098988)

15 van Mierlo LA, Koning MM, van der Zander K \& Draijer R. Lactotripeptides do not lower ambulatory blood pressure in untreated whites: results from 2 controlled multicenter crossover studies. American Journal of Clinical Nutrition 200989 617-623. (doi:10.3945/ ajcn.2008.26918)

16 Cicero AF, Rosticci M, Veronesi M, Bacchelli S, Strocchi E, Melegari C, Grandi E \& Borghi C. Hemodynamic effects of lactotripeptides from casein hydrolysate in Mediterranean normotensive subjects and patients with high-normal blood pressure: a randomized, double-blind crossover clinical trial. Journal of Medicinal Food 201013 1363-1368. (doi:10.1089/jmf.2009.0253)

17 Jauhiainen T, Vapaatalo H, Poussa T, Kyronpalo S, Rasmussen M \& Korpela R. Lactobacillus helveticus fermented milk lowers blood pressure in hypertensive subjects in 24-h ambulatory blood pressure measurement. American Journal of Hypertension 200518 1600-1605. (doi:10.1016/j.amjhyper.2005.06.006)

18 Cicero AF, Gerocarni B, Laghi L \& Borghi C. Blood pressure lowering effect of lactotripeptides assumed as functional foods: a meta-analysis of current available clinical trials. Journal of Human Hypertension 2011 25 425-436. (doi:10.1038/jhh.2010.85)

19 Pripp AH. Effect of peptides derived from food proteins on blood pressure: a meta-analysis of randomized controlled trials. Food \& Nutrition Research 200852 1-9. (doi:10.3402/fnr.v52i0.1641)

20 Xu JY, Qin LQ, Wang PY, Li W \& Chang C. Effect of milk tripeptides on blood pressure: a meta-analysis of randomized controlled trials. Nutrition 200824 933-940. (doi:10.1016/j.nut.2008.04.004)

21 Cicero AF, Aubin F, Azais-Braesco V \& Borghi C. Do the lactotripeptides isoleucine-proline-proline and valine-proline-proline reduce systolic blood pressure in European subjects? A meta-analysis of randomized controlled trials. American Journal of Hypertension 201326 442-449. (doi:10.1093/ajh/hps044)

22 Fuglsang A, Nilsson D \& Nyborg NC. Cardiovascular effects of fermented milk containing angiotensin-converting enzyme inhibitors evaluated in permanently catheterized, spontaneously hypertensive rats. Applied and Environmental Microbiology 200268 3566-3569. (doi:10.1128/AEM.68.7.3566-3569.2002)

23 Pierdomenico SD, Bucci A, Lapenna D, Cuccurullo F \& Mezzetti A. Heart rate in hypertensive patients treated with ACE inhibitors and long-acting dihydropyridine calcium antagonists. Journal of Cardiovascular Pharmacology 200240 288-295. (doi:10.1097/ 00005344-200208000-00014)

24 Jensen MT, Marott JL, Allin KH, Nordestgaard BG \& Jensen GB. Resting heart rate is associated with cardiovascular and all-cause mortality after adjusting for inflammatory markers: the Copenhagen City Heart Study. European Journal of Preventive Cardiology 201219 102-108. (doi:10.1177/1741826710394274)

25 Palatini P. Elevated heart rate in cardiovascular diseases: a target for treatment? Progress in Cardiovascular Diseases 200952 46-60. (doi:10.1016/j.pcad.2009.05.005)

26 DeFronzo RA. Pathogenesis of type 2 diabetes mellitus. Medical Clinics of North America 200488 787-835, ix. (doi:10.1016/j.mcna. 2004.04.013)

27 Dahlof B, Devereux RB, Kjeldsen SE, Julius S, Beevers G, de Faire U, Fyhrquist $\mathrm{F}$, Ibsen $\mathrm{H}$, Kristiansson $\mathrm{K}$, Lederballe-Pedersen $\mathrm{O}$ et al. 
Cardiovascular morbidity and mortality in the Losartan Intervention For Endpoint reduction in hypertension study (LIFE): a randomised trial against atenolol. Lancet 2002359 995-1003. (doi:10.1016/S01406736(02)08089-3)

28 Hansson L, Hedner T, Lindholm L, Niklason A, Luomanmaki K, Niskanen L, Lanke J, Dahlof B, de Faire U, Morlin C et al. The Captopril Prevention Project (CAPPP) in hypertension - baseline data and current status. Blood Pressure 1997 6 365-367. (doi:10.3109/ 08037059709062096)

29 Julius S, Weber MA, Kjeldsen SE, McInnes GT, Zanchetti A, Brunner HR, Laragh J, Schork MA, Hua TA, Amerena J et al. The Valsartan Antihypertensive Long-Term Use Evaluation (VALUE) trial: outcomes in patients receiving monotherapy. Hypertension 200648 385-391. (doi:10.1161/01.HYP.0000236119.96301.f2)

30 Yusuf S, Gerstein H, Hoogwerf B, Pogue J, Bosch J, Wolffenbuttel BH, Zinman B \& HS Investigators. Ramipril and the development of diabetes. Journal of the American Medical Association 2001286 1882-1885. (doi:10.1001/jama.286.15.1882)

31 Jauch KW, Hartl W, Guenther B, Wicklmayr M, Rett K \& Dietze G. Captopril enhances insulin responsiveness of forearm muscle tissue in non-insulin-dependent diabetes mellitus. European Journal of Clinical Investigation 1987 17 448-454. (doi:10.1111/j.1365-2362.1987.tb01141.x)

32 Torlone E, Rambotti AM, Perriello G, Botta G, Santeusanio F, Brunetti P $\&$ Bolli GB. ACE-inhibition increases hepatic and extrahepatic sensitivity to insulin in patients with type 2 (non-insulin-dependent) diabetes mellitus and arterial hypertension. Diabetologia 199134 119-125. (doi:10.1007/BF00500383)
33 Suzuki K, Nakagawa O \& Aizawa Y. Improved early-phase insulin response after candesartan treatment in hypertensive patients with impaired glucose tolerance. Clinical and Experimental Hypertension 2008 30 309-314. (doi:10.1080/10641960802269927)

34 Festa ADARJ, D'Agostino R Jr, Howard G, Mykkänen L, Tracy RP \& Haffner SM. Chronic subclinical inflammation as part of the insulin resistance syndrome: the Insulin Resistance Atherosclerosis Study (IRAS). Circulation 2000102 42-47. (doi:10.1161/01.CIR.102.1.42)

35 Libby P, Ridker PM \& Maseri A. Inflammation and atherosclerosis. Circulation 2002105 1135-1143. (doi:10.1161/hc0902.104353)

36 Panwar H, Rashmi HM, Batish VK \& Grover S. Probiotics as potential biotherapeutics in the management of type 2 diabetes - prospects and perspectives. Diabetes/Metabolism Research and Reviews 201329 103-112. (doi:10.1002/dmrr.2376)

37 Goldberg RB. Cytokine and cytokine-like inflammation markers, endothelial dysfunction, and imbalanced coagulation in development of diabetes and its complications. Journal of Clinical Endocrinology and Metabolism 200994 3171-3182. (doi:10.1210/jc.2008-2534)

38 Haro C, Villena J, Zelaya H, Alvarez S \& Aguero G. Lactobacillus casei modulates the inflammation-coagulation interaction in a pneumococcal pneumonia experimental model. Journal of Inflammation 2009 6 28. (doi:10.1186/1476-9255-6-28)

39 Grundy SM. Small LDL, atherogenic dyslipidemia, and the metabolic syndrome. Circulation 199795 1-4. (doi:10.1161/01.CIR.95.1.1)

40 Beermann C \& Hartung J. Physiological properties of milk ingredients released by fermentation. Food \& Function 20134 185-199. (doi:10.1039/c2fo30153a)

Received 3 July 2014

Revised version received 2 October 2014

Accepted 9 October 2014 